Case Reports in
Gastroenterology
Case Rep Gastroenterol 2021;15:232-243

DOI: $10.1159 / 000512420$

Published online: February 18, 2021 (c) 2021 The Author(s)

Published by S. Karger AG, Basel www.karger.com/crg

This article is licensed under the Creative Commons Attribution-NonCommercial 4.0 International License (CC BY-NC) (http://www.karger.com/Services/OpenAccessLicense). Usage and distribution for commercial purposes requires written permission.

\title{
Eosinophilic Cholangitis with Poor Prognosis after Corticosteroid- and Ursodeoxycholic Acid-Related Remission of Peripheral and Peribiliary Eosinophilia
}

\author{
Takahito Shimomura $^{a}$ Tomoki Nakajima $^{a}$ Toshiaki Nakashima ${ }^{a}$ \\ Yasutaka Morimoto $^{a}$ Junko Yamaoka ${ }^{a}$ Akiko Shibuya ${ }^{a}$ \\ Tomoyuki Ohno $^{a}$ Norimasa Yoshida ${ }^{a}$ Mitsuo Kishimoto ${ }^{b}$ \\ Eiichi Konishi $^{b}$ Hideo Tanaka ${ }^{b}$ Michihisa Moriguchic ${ }^{c}$ Yoshito Itoh $^{c}$ \\ aDepartment of Internal Medicine, Saiseikai Kyoto Hospital, Nagaoka-Kyo, Japan; \\ ${ }^{b}$ Department of Pathology, Graduate School of Medical Science, Kyoto Prefectural \\ University of Medicine, Kyoto, Japan; 'Department of Molecular Gastroenterology and \\ Hepatology, Graduate School of Medical Science, Kyoto Prefectural University of \\ Medicine, Kyoto, Japan
}

\section{Keywords}

Eosinophilic cholangitis · Sclerosing cholangitis · Eosinophilic cholecystitis

\begin{abstract}
A 79-year-old man presented with high fever, marked eosinophilia, altered biochemical liver function tests (LFT) with predominance of biliary enzymes, and severe wall thickening of the gallbladder. Magnetic resonance cholangiopancreatography (MRCP) suggested cholecystitis, without signs of biliary strictures. Laparoscopic cholecystectomy and exploratory liver excision revealed eosinophilic cholangitis and cholecystitis, complicated with hepatitis and portal phlebitis. Prednisolone monotherapy rapidly improved peripheral eosinophilia, but not LFT. Liver biopsy showed that infiltrating eosinophils were replaced by lymphocytes and plasma cells. Treatment with ursodeoxycholic acid improved LFT abnormalities. Nevertheless, after 2 months, transaminase-dominant LFT abnormalities appeared. Transient prednisolone dose
\end{abstract}

\begin{tabular}{ll}
\hline & Tomoki Nakajima \\
& Affiliation Saiseikai Kyoto Hospital \\
& Minamihirao-8, Imazato \\
& Nagaoka-Kyo 617-0814, Kyoto Prefecture (Japan) \\
tomnaka624@zeus.eonet.ne.jp
\end{tabular}




\section{Case Reports in Gastroenterology}

Case Rep Gastroenterol 2021;15:232-243

DOI: $10.1159 / 000512420$

(C) 2021 www.karger.com/crg

Shimomura et al: Eosinophilic Cholangitis with Poor Prognosis after Corticosteroid- and Ursodeoxycholic Acid-Related Remission of Peripheral and Peribiliary Eosinophilia

increase improved LFT, but biliary enzymes' levels re-elevated and jaundice progressed. The second and third MRCP within a 7-month interval showed rapid progression of biliary stricture. The repeated liver biopsy showed lymphocytic, not eosinophilic, peribiliary infiltration and hepatocellular reaction to cholestasis. Eighteen months after the first visit, the patient died of hepatic failure. Autopsy specimen of the liver showed lymphocyte-dominant peribiliary infiltration and bridging fibrosis due to cholestasis. Though eosinophil-induced biliary damage was an initial trigger, repeated biopsy suggested that lymphocytes played a key role in progression of the disease. Further studies are needed to elucidate the relationship between eosinophils and lymphocytes in eosinophilic cholangitis.

(C) 2021 The Author(s)

Published by S. Karger AG, Basel

\section{Introduction}

Sclerosing cholangitis is classified into two entities, primary sclerosing cholangitis (PSC) and secondary sclerosing cholangitis (SSC) [1,2]. SSC is caused by known pathological entities, such as IgG4-related autoimmune pancreatitis, eosinophilic cholangitis, cholelithiasis, surgical or blunt abdominal trauma, intra-arterial chemotherapy, and AIDS-related cholangiopathy [1, 2].

Eosinophilic cholangitis (EC) is a rare condition characterized by eosinophilic infiltration of the biliary tract with or without peripheral eosinophilia, and has potential to cause sclerosing cholangitis [1,3-6]. Although most patients show favorable response to corticosteroid therapy, in some patients treated without prednisolone or other immunosuppressive agents, or in whom immunosuppression was withdrawn, clinical conditions or laboratory tests deteriorated. Furthermore, in cases of advanced hepatic damage or disease recurrence, long-term immunosuppression is needed [7-10]. The reasons for such therapeutic outcomes are not sufficiently known. Experimental studies have demonstrated a close relationship between eosinophilia and biliary fibrosis, suggesting that the control of eosinophilia may be a key to successful treatment of EC $[11,12]$.

However, here we present a case of an older patient who showed rapidly progressive sclerosing cholangitis leading to hepatic failure despite corticosteroid- and ursodeoxycholic acid-related remission of peripheral and peribiliary eosinophilia. This suggests that successful pharmacological control of eosinophilia does not necessarily stop or reverse biliary damage due to EC.

\section{Case Presentation}

A 79-year-old man visited our clinic complaining of high fever and general fatigue. Fever developed 8 days before the first visit. Despite use of antipyretics prescribed by a local physician, fever continued and general fatigue aggravated, and he was finally admitted to our hospital. Physical examination revealed no remarkable findings on chest and abdomen. There was slight conjunctival icterus as well as skin rash at the trunk and both thighs. The skin lesions consisted of disseminated erythema and partially coalescent red papules. His body temperature was $37.6^{\circ} \mathrm{C}$, blood pressure $-148 / 88 \mathrm{~mm} \mathrm{Hg}$, and heart rate $-96 / \mathrm{min}$.

Laboratory studies showed marked eosinophilia. Specifically, while total white blood cell count was 15,500, differential cell count showed 50.0\% eosinophils, $37.0 \%$ neutrophils, $6.0 \%$

\section{Karger'=}




\section{Case Reports in Gastroenterology}

Case Rep Gastroenterol 2021;15:232-243

DOI: $10.1159 / 000512420$

(c) 2021 The Author(s). Published by S. Karger AG, Basel www.karger.com/crg

Shimomura et al.: Eosinophilic Cholangitis with Poor Prognosis after Corticosteroid- and Ursodeoxycholic Acid-Related Remission of Peripheral and Peribiliary Eosinophilia

monocytes, 5.0\% lymphocytes, and 1.0\% myelocytes. Liver function tests (LFT) were abnormal with dominant abnormalities in biliary enzymes: aspartate aminotransferase (AST), 79 IU/L; alanine aminotransferase (ALT), $236 \mathrm{IU} / \mathrm{L}$; alkaline phosphatase (ALP), 1,383 IU/L; $\gamma$ glutamyl transferase ( $\gamma$-GTT), $390 \mathrm{IU} / \mathrm{L}$; total bilirubin, $2.4 \mathrm{mg} / \mathrm{mL}$. His serum C-reactive protein level was $7.62 \mathrm{mg} / \mathrm{dL}$. IgG4 level was within normal range. Autoantibodies, such as antinuclear antibodies (ANA), anti-mitochondrial antibodies (AMA), myeloperoxidase-anti-neutrophil cytoplasmic antibodies (MPO-ANCA), and serine proteinase3-anti-neutrophil cytoplasmic antibodies (PR3-ANCA), were negative.

Magnetic resonance cholangiopancreatography (MRCP) at the first visit revealed severely edematous wall of the gallbladder, but no signs of stricture of intrahepatic and extrahepatic biliary ducts (Fig. 1a). Computed tomography (CT) at the first visit demonstrated edematous wall thickening of the gallbladder without cholelithiasis (Fig. 1d). Skin rash and eosinophilia prevented us from using contrast medium. Considering marked peripheral eosinophilia, we suspected eosinophilic cholecystitis. To confirm the diagnosis, we performed laparoscopic cholecystectomy on day 7. Intraoperative liver biopsy was also performed at the same time.

Histological examination of the resected gallbladder revealed erosions of mucosal layer and massive infiltration of all layers of the wall with inflammatory cells mainly consisting of eosinophils (Fig. 2a). The findings of vasculitis, such as extravasation of erythrocytes and nuclear swelling of endothelial cells, were scarcely seen. Bacterial culture test of the bile in the gallbladder was negative. Taken together, we confirmed the diagnosis of eosinophilic cholecystitis.

Histological examination of the excised liver tissue showed widening of the periportal areas with interface hepatitis accompanied with remarkable infiltration predominantly with eosinophils, which is compatible with eosinophilic hepatitis (Fig. 2b, c). Besides, destroyed biliary ducts and portal branches with massive eosinophilic infiltration were occasionally seen, suggesting eosinophilic intrahepatic cholangitis (Fig. 2d) and portal phlebitis, respectively (Fig. 2e, f).

Eight days after the initial admission, oral administration of $40 \mathrm{mg} /$ day of prednisolone was started to regulate eosinophilic hepatitis, cholangitis, and portal phlebitis. As expected, peripheral eosinophilia disappeared, but transaminases and biliary enzymes exacerbated (Fig. 3). To evaluate histological changes after corticosteroid therapy, we performed the first needle liver biopsy 13 days after the first admission. The liver specimen showed moderately to severely widened portal areas with moderate to severe infiltration by inflammatory cells, accompanied with mild to moderate fibrosis (Fig. 4a). It was noteworthy that infiltrating eosinophils almost disappeared and that they were replaced by lymphocytes and plasma cells (Fig. 4b), mimicking autoimmune hepatitis (AIH). The bile ductules slightly decreased in number, suggesting that they were destroyed by cholangitis. In the liver parenchyma, spotty necrosis and focal necrosis with lymphocytic and plasma cell infiltration were observed (Fig. 4c). The signs of portal phlebitis disappeared. We continued administration of prednisolone hoping that it would be effective for AIH-like chronic hepatitis. Besides, we added ursodeoxycholic acid (UDCA) for cytoprotection of biliary ducts. As a result, both the levels of transaminases and biliary enzymes decreased (Fig. 3).

However, 2 months after the first visit, LFT revealed the upsurge of the levels of transaminases and biliary enzymes (Fig. 5). To re-evaluate histological findings, the second needle liver biopsy was performed 3 months after the first visit. We observed the signs of mild lobular and interface hepatitis with a small number of infiltrating eosinophils and lymphocytes (Fig. $4 \mathrm{~d}, \mathrm{e}$ ), and reduced degree of fibrosis to a very mild level (Fig. 4f). Contrary to the worsening

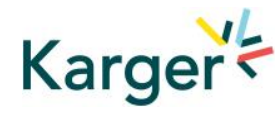




\section{Case Reports in Gastroenterology}

Case Rep Gastroenterol 2021;15:232-243

DOI: $10.1159 / 000512420$

(c) 2021 The Author(s). Published by S. Karger AG, Basel www.karger.com/crg

Shimomura et al.: Eosinophilic Cholangitis with Poor Prognosis after Corticosteroid- and Ursodeoxycholic Acid-Related Remission of Peripheral and Peribiliary Eosinophilia

clinical data, the pathohistological findings improved, and therefore, the disease appeared to be prednisolone-responsive hepatitis. We increased the dose of prednisolone up to 60 $\mathrm{mg} /$ day, and then, the level of transaminases gradually decreased to nearly the normal range. The levels of biliary enzymes also decreased, but stayed over the upper normal limit. Seven months after the first visit, MRCP showed dilatation of the common bile duct, which was mainly interpreted as the result of cholecystectomy (Fig. 1b). Moreover, the images of some intrahepatic bile ducts were suggestive of biliary stenosis and post-stenotic dilatation (Fig. 1b). We transiently added $50-100 \mathrm{mg}$ /day of azathioprine to prednisolone, but re-upsurge of the levels of biliary enzymes was observed (Fig. 5).

For histological reassessment of the liver, the third needle biopsy was performed 10 months after the first visit. The liver specimen showed interface hepatitis with massive infiltration with lymphocytes that occasionally formed lymph follicles (Fig. 6a, b). Eosinophilic infiltration was scarcely observed. Spotty necrosis was scattered. In addition, there were signs of bile stasis, such as intracytoplasmic bile pigment, bile plugs in the bile canaliculi (Fig. 6c), and feathery degeneration (Fig. 6d). Some hepatocytes presented as multinucleated giant cells (Fig. 6d), indicating the hepatocellular reaction to cholestatic injury. Portal fibrosis showed a slight trend to extension toward the adjacent portal areas (Fig. 6e).

By the time of the third liver biopsy, prednisolone was successfully tapered without reupsurge of transaminases. Nevertheless, the levels of biliary enzymes gradually elevated (Fig. 5) along with overt jaundice, which was suggestive of progressive biliary stasis. Fourteen months after the first visit, MRCP and endoscopic retrograde cholangiopancreatography (ERCP) showed multiple stenoses of intrahepatic bile ducts, thereby mimicking typical imaging signs of PSC (Fig. 1c). Liver failure due to cholestasis progressed and the patient died of gastrointestinal bleeding 18 months after the first visit (Fig. 5).

At autopsy, the dark green liver weighing $723 \mathrm{~g}$ showed slightly micronodular appearance (Fig. 7a). Microscopically, hepatic infiltration with lymphocytes, not eosinophils, was observed. Obstruction and destruction of the septal biliary ducts and bile canaliculi resulted in bile stasis. Reactive to such biliary damage, ductular proliferation was also observed. Obstruction and destruction of the interlobular biliary ducts resulted in bile stasis and periductular fibrosis that extended to the adjacent portal areas and formed bridging fibrosis (Fig. 7b, c).

\section{Discussion}

EC is a rare, benign disease characterized by transmural eosinophilic infiltration of the biliary tree leading to strictures and obstruction $[1,3-6]$. It is not necessarily accompanied with peripheral eosinophilia. The range of the lesions in EC varies from case to case; some patients present only focal changes of biliary tree, while others experience complications in form of cholecystitis and widespread biliary stenoses [13]. EC may be a diagnostic challenge, especially in patients without peripheral eosinophilia who present biliary stricture mimicking neoplastic biliary obstruction [14-18].

At the first visit, our patient showed marked eosinophilia, normal MRCP image of the common bile duct, and severely thickened wall of the gallbladder, which was suggestive of eosinophilic cholecystitis. However, marked elevation of biliary enzymes and moderate increase in transaminases were indicators of cholestasis and hepatocellular injury, and were not explainable by cholecystitis alone. Therefore, our further diagnostic strategy included exploratory excision of the hepatic tissue in addition to laparoscopic cholecystectomy. This procedure

\section{Karger'=}




\section{Case Reports in Gastroenterology}

Case Rep Gastroenterol 2021;15:232-243

DOI: $10.1159 / 000512420$

(c) 2021 The Author(s). Published by S. Karger AG, Basel www.karger.com/crg

Shimomura et al.: Eosinophilic Cholangitis with Poor Prognosis after Corticosteroid- and Ursodeoxycholic Acid-Related Remission of Peripheral and Peribiliary Eosinophilia

showed us that cholecystitis, hepatitis, intrahepatic cholangitis, and poral phlebitis were all associated with massive eosinophilic infiltration.

Our present case demonstrated that marked peripheral eosinophilia disappeared 6 days after the initiation of $40 \mathrm{mg} /$ day of prednisolone. The first needle biopsy of the liver performed on the same day showed that eosinophils were replaced by lymphocytes and plasma cells infiltrating the portal areas. The second needle biopsy showed the presence of mild eosinophilic infiltration of the portal areas, possibly because the effect of prednisolone was diminished during tapering. Horiguchi et al. [19] also demonstrated the reduction of eosinophilia after the initiation of UDCA for EC. They speculated that peripheral eosinophilia and eosinophilic infiltration play an important role in the initial pathogenesis of EC [19]. However, disappearance of eosinophilia was accompanied with lymphocytic infiltration [19], which raises the question about their role in the pathophysiology of EC. MRCP images demonstrated the progression of biliary stricture in our patient. To date, there is only one case report of EC presenting the progressive changes in biliary stricture on MRCP images [8]. In that report, MRCP initially presented almost normal findings, followed by progression into diffuse sclerosing and narrowing of the biliary tree, and finally the images mimicking PSC. Our present report demonstrated similar sequential changes in MRCP images. Namely, the initial MRCP showed almost normal findings of biliary ducts, while 7 months later, the second MRCP showed not only post-cholecystectomy dilatation of the common biliary duct, but also focal intrahepatic biliary stenosis and post-stenotic dilatation. Fourteen months after the first visit, the third MRCP showed multiple stenoses and post-stenotic dilatation of intrahepatic biliary ducts throughout the liver, mimicking the typical image of PSC.

The third liver biopsy was performed during the interval between the second and third MRCP, when intrahepatic biliary stricture radiographically progressed. In a biopsy specimen, bile pigment in hepatocytes, bile plug in bile canaliculi, and feathery degeneration of hepatocytes were noted, all of which were suggestive of cholestatic hepatocellular injury. Observed multinucleated giant hepatocytes are considered to be the result of the fusion of individual cells or failure of the cytoplasm to divide at the time of nuclear division [20]. Hence, we can speculate that this transformation is the defective product of the cell-cycle turnover reaction to various hepatocellular injuries. Moreover, this transformation in adults is particularly observed in the pathophysiology of autoimmunity and cholestasis [21]. It is noteworthy that, under such cholestatic state, histological findings demonstrated massive, predominantly lymphocytic infiltration at the portal areas, while eosinophils were rarely observed. These clinical and pathohistological findings suggested that lymphocytes played a key role in progression of biliary stricture in the condition of cholestasis.

Activated eosinophils may cause direct cell injury via release of a cationic major basic protein [11]. In addition to such direct action, activated eosinophils also produce various cytokines leading to inflammation and fibrotic changes in the wall of the biliary ducts [12]. Hence, peripheral eosinophilia and eosinophilic infiltration seem to be crucial for understanding the pathophysiology of EC. However, biliary stricture progressed after peripheral eosinophilia and eosinophilic infiltration subsided in our case. In this context, we assume that though the lymphocytes were not dominant at the initial stage, they were activated prior to the progressive stage and played a major role after eosinophils were suppressed by the therapy.

In primary biliary cholangitis (PBC, which was former named as primary biliary cirrhosis) and PSC, it is generally considered that lymphocytes predominantly infiltrate around the biliary tree prior to the scarring stage [22]. In PBC, abundant infiltration of cytotoxic T lymphocytes into portal areas positively correlated with the level of biliary enzymes and hepatic

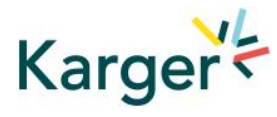




\section{Case Reports in Gastroenterology}

Case Rep Gastroenterol 2021;15:232-243

DOI: $10.1159 / 000512420$

(c) 2021 The Author(s). Published by S. Karger AG, Basel www.karger.com/crg

Shimomura et al.: Eosinophilic Cholangitis with Poor Prognosis after Corticosteroid- and Ursodeoxycholic Acid-Related Remission of Peripheral and Peribiliary Eosinophilia

fibrosis, which is suggestive of a key role of lymphocytes during active remodeling stage prior to scarring [23]. Furthermore, in PSC complicated with inflammatory bowel disease, mutual trafficking pathways of lymphocytes between the gut and hepatobiliary target tissues were found to be important at a progressive stage [24]. This sequential course indicates that lymphocytes play a key role in the progression of biliary damage, though we cannot neglect that lymphocytic infiltration was also affected by concurrently ongoing cholestasis [25]. According to the previous reports, in some cases of PBC and PSC, peripheral eosinophilia and eosinophilic infiltration were seen particularly at an early stage of the diseases [23, 24]. Therefore, it is conceivable that the reduction of eosinophils and appearance of lymphocyte-dominancy at a progressive stage similarly occurs in EC-based SSC.

Most cases of EC show good response to corticosteroids [7-9]. Therefore, some authors even proposed that steroid-responsiveness should be included in clinical diagnostic criteria of EC [5]. However, despite the treatment with a corticosteroid, UDCA, and short-term with an immunosuppressive agent, our present case showed rapidly progressive clinical course. In the hepatic tissue initially obtained by exploratory excision, we observed eosinophilic cholangitis, hepatitis, and portal phlebitis. At autopsy, lymphocytic, not eosinophilic, infiltration was observed, and bridging fibrosis was formed due to cholestasis as a result of the stricture of biliary ducts. There were no histological signs of phlebitis. Therefore, we assumed that the treatment with prednisolone and UDCA obviously controlled portal eosinophilic infiltration and phlebitis, but failed to stop or reverse the rapid progression of biliary stricture and peribiliary fibrosis due to cholestasis. Though most cases of EC basically show good prognosis if the immunosuppressive therapy is used and continued [10], it is not known why our case showed exceptionally poor therapeutic response. For better understanding of the pathophysiology at the progressive stage of biliary stricture in EC, further investigations on the immunological interactions between eosinophils and lymphocytes in EC and their overall effects on various types of injured cells and tissues, such as biliary ducts, hepatocytes and portal veins are needed.

\section{Acknowledgments}

All authors would like to acknowledge Dr. Yasuni Nakanuma for providing and reviewing the histopathology slides.

\section{Statement of Ethics}

The study was performed in accordance with the ethical standards laid down in the 1964 Declaration of Helsinki and its subsequent amendments.

We obtained the informed consent from the patient in a written form prior to all invasive diagnostic and therapeutic procedures, such as laparoscopic cholecystectomy, exploratory excision of the liver, and three times of needle liver biopsy. In addition, when he was alive, he consented to autopsy after his death. We also obtained the informed consent on autopsy from his daughter. Prior to manuscript submission, we obtained the consent to publish the case from her.

\section{Karger'=}


Case Reports in
Gastroenterology

Case Rep Gastroenterol 2021;15:232-243

DOI: $10.1159 / 000512420$

(c) 2021 The Author(s). Published by S. Karger AG, Basel www.karger.com/crg

Shimomura et al: Eosinophilic Cholangitis with Poor Prognosis after Corticosteroid- and Ursodeoxycholic Acid-Related Remission of Peripheral and Peribiliary Eosinophilia

\section{Conflict of Interest Statement}

The authors have no conflicts of interest to disclose.

\section{Author Contributions}

All authors wrote and edited the manuscript. Tomoki Nakajima is the article guarantor.

\section{References}

1 Abdalian R, Heathcote EJ. Sclerosing cholangitis: a focus on secondary causes. Hepatology. 2006 Nov;44(5):1063-74.

2 Gossard AA, Angulo P, Lindor KD. Secondary sclerosing cholangitis: a comparison to primary sclerosing cholangitis. Am J Gastroenterol. 2005 Jun;100(6):1330-3.

3 Butler TW, Feintuch TA, Caine WP Jr. Eosinophilic cholangitis, lymphadenopathy, and peripheral eosinophilia: a case report. Am J Gastroenterol. 1985 Jul;80(7):572-4.

4 Rosengart TK, Rotterdam H, Ranson JH. Eosinophilic cholangitis: a self-limited cause of extrahepatic biliary obstruction. Am J Gastroenterol. 1990 May;85(5):582-5.

5 Matsumoto N, Yokoyama K, Nakai K, Yamamoto T, Otani T, Ogawa M, et al. A case of eosinophilic cholangitis: imaging findings of contrast-enhanced ultrasonography, cholangioscopy, and intraductal ultrasonography. World J Gastroenterol. 2007 Apr;13(13):1995-7.

6 Duseja A, Nada R, Dhiman RK, Chawla YK, Kalra N, Prashad S, et al. Eosinophilic cholangiopathy-a case report. Dig Dis Sci. 2005 Aug;50(8):1422-5.

7 Nashed C, Sakpal SV, Shusharina V, Chamberlain RS. Eosinophilic cholangitis and cholangiopathy: a sheep in wolves clothing. HPB Surg. 2010;2010:906496.

8 Kimura Y, Yamashita Y, Mikami S, Ono H, Itai R, Matsumoto Y, et al. [Eosinophilic cholangitis from almost normal appearance to the bile duct sclerosis similar to primary sclerosing cholangitis]. Nihon Shokakibyo Gakkai Zasshi. 2013 Feb;110(2):271-81. Japanese.

9 De Roza MA, Lim CH. Eosinophilic cholangitis treatment with budesonide. World J Hepatol. 2017 Dec;9(36):1385-8.

10 Reher D, Schramm C, Brinkert F, Weidemann SA, Plauth M, Lohse AW, et al. Immunosuppression as effective therapy for eosinophilic cholangiopathy: A case series and review of the literature. GastroHep. 2019;1(1):33-44.

11 Noguchi H, Kephart GM, Colby TV, Gleich GJ. Tissue eosinophilia and eosinophil degranulation in syndromes associated with fibrosis. Am J Pathol. 1992 Feb;140(2):521-8.

12 Diny NL, Rose NR, Čiháková D. C`iháková D. Eosinophils in autoimmune diseases. Front Immunol. 2017 Apr;8:484.

13 Vitellas KM, Keogan MT, Freed KS, Enns RA, Spritzer CE, Baillie JM, et al. Radiologic manifestations of sclerosing cholangitis with emphasis on MR cholangiopancreatography. Radiographics. 2000 JulAug;20(4):959-75.

14 Fragulidis GP, Vezakis AI, Kontis EA, Pantiora EV, Stefanidis GG, Politi AN, et al. Eosinophilic cholangitis - a challenging diagnosis of benign biliary stricture: a case report. Medicine (Baltimore). 2016 Jan;95(1):e2394.

15 Hammami MB, Ohanisian L, Kaur N, Irshad A, Sidley A. A challenging diagnosis of eosinophilic cholangitis requiring resection of extrahepatic bile ducts. Cureus. 2019 Jun;11(6):e4925.

16 Dodda A, Matsukuma K, Urayama S. Eosinophilic cholangitis: A case report of diagnostically challenging eosinophilic infiltrative biliary obstruction. World J Gastrointest Endosc. 2019 Dec;11(12):589-95.

17 Hoilat JN, Hoilat GJ, AlQahtani S, Alhussaini HF, Alabbad SI. Atypical presentation of a rare disease: eosinophilic cholangitis posing as a cancer. Am J Case Rep. 2018 Jan;19:76-81.

18 Akolkar S, Patel J, Abdu B, Sorser S. The cloaked intruder: an unexpected case of eosinophilic cholangitis ACG Case Rep J. 2019 Nov;6(11):e00235.

19 Horiuchi K, Kakizaki S, Kosone T, Ichikawa T, Sato K, Takagi H, et al. Marked eosinophilia as the first manifestation of sclerosing cholangitis. Intern Med. 2009;48(16):1377-82.

20 Thaler H. Post-infantile giant cell hepatitis. Liver. 1982 Dec;2(4):393-403.

21 Ben-Ari Z, Broida E, Monselise Y, Kazatsker A, Baruch J, Pappo O, et al. Syncytial giant-cell hepatitis due to autoimmune hepatitis type II (LKM1+) presenting as subfulminant hepatitis. Am J Gastroenterol. 2000 Mar;95(3):799-801.

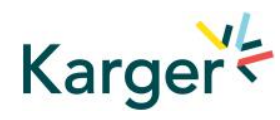




\section{Case Reports in Gastroenterology}

\begin{tabular}{l|l}
\hline Case Rep Gastroenterol 2021;15:232-243 \\
\hline DOI: 10.1159/000512420 & $\begin{array}{l}\text { @ 2021 The Author(s). Published by S. Karger AG, Basel } \\
\text { www.karger.com/crg }\end{array}$ \\
\hline
\end{tabular}

Shimomura et al.: Eosinophilic Cholangitis with Poor Prognosis after Corticosteroid- and Ursodeoxycholic Acid-Related Remission of Peripheral and Peribiliary Eosinophilia

22 Zen Y, Hubscher SG, Nakanuma Y. Chapter 9: Bile duct diseases. In: Burt AD, Ferrell LD, Hubscher SG, editors. MacSween's Pathology of the Liver. Churchill Livingstone; 1994. pp. 515-93.

23 Yamazaki K, Nakadate I, Suzuki K, Sato S, Masuda T. Eosinophilia in primary biliary cirrhosis. Am J Gastroenterol. 1996 Mar;91(3):516-22.

24 Watanabe H, Ohira H, Kuroda M, Takagi T, Ishikawa H, Nishimaki T, et al. Primary sclerosing cholangitis with marked eosinophilic infiltration in the liver. J Gastroenterol. 1995 Aug;30(4):524-8.

25 Li Y, Li B, You Z, Zhang J, Wei Y, Li Y, et al. Cytotoxic KLRG1 expressing lymphocytes invade portal tracts in primary biliary cholangitis. J Autoimmun. 2019 Sep;103:102293.
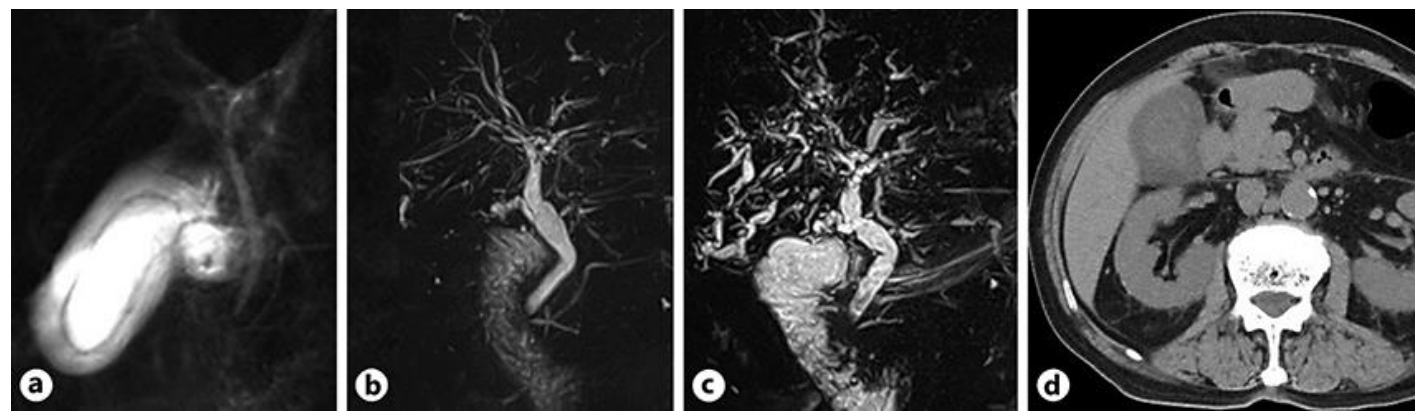

Fig. 1. Characteristic radiographical findings are shown. a-c Sequential changes in the images of magnetic resonance cholangiopancreatography. a At the first visit: severely edematous wall of the gallbladder, but no signs of intrahepatic and extrahepatic biliary stricture were seen. $\mathbf{b}$ Seven months after the first visit: in addition to post-cholecystectomy dilatation of the common biliary duct, intrahepatic biliary stenosis and post-stenotic dilatation in some parts of the liver were observed. c Fourteen months after the first visit: multiple stenoses and post-stenotic dilatation of the intrahepatic biliary ducts were observed throughout the liver, mimicking the typical image of primary sclerosing cholangitis. $\mathbf{d}$ CT image at the first visit: the gallbladder shows edematous wall thickening without cholelithiasis. 


\section{Case Reports in Gastroenterology}

\begin{tabular}{l|l}
\hline Case Rep Gastroenterol 2021;15:232-243 \\
\hline DOI: 10.1159/000512420 & $\begin{array}{l}\text { @ 2021 The Author(s). Published by S. Karger AG, Basel } \\
\text { www.karger.com/crg }\end{array}$ \\
\hline
\end{tabular}

Shimomura et al.: Eosinophilic Cholangitis with Poor Prognosis after Corticosteroid- and Ursodeoxycholic Acid-Related Remission of Peripheral and Peribiliary Eosinophilia
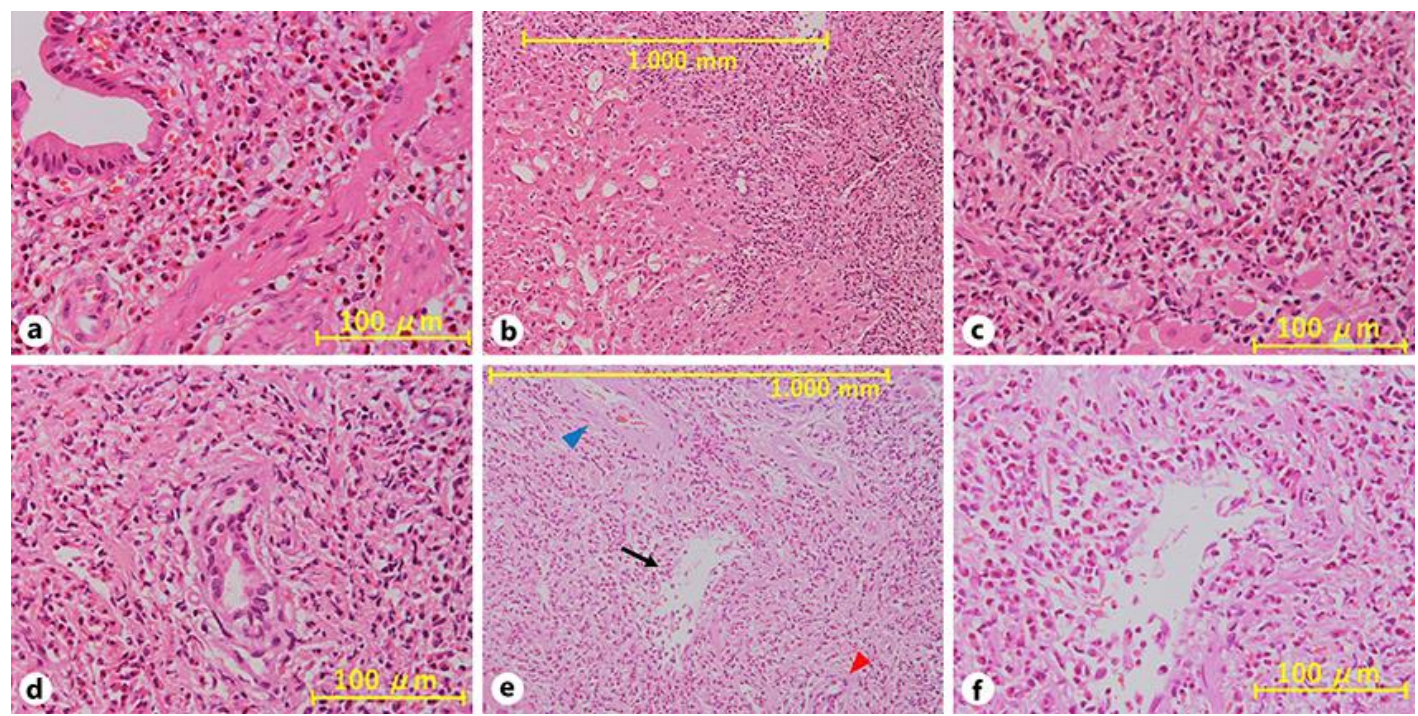

Fig. 2. Pathohistological findings of resected gallbladder and excised liver tissue (hematoxylin/eosin staining, HE). a Massive infiltration of all layers of the gallbladder wall with inflammatory cells mainly consisting of eosinophils. b Widening of the portal areas with interface hepatitis accompanied with massive infiltration with inflammatory cells. c Note that the infiltrating cells are mainly eosinophils. $\mathbf{d}$ Destroyed biliary ducts in the portal areas. e Portal phlebitis. Destroyed portal vein (black arrow). The arterial vessel is indicated by a blue arrowhead and the biliary duct by a red arrowhead. $\mathbf{f}$ Massive eosinophilic infiltration around the injured portal vein.

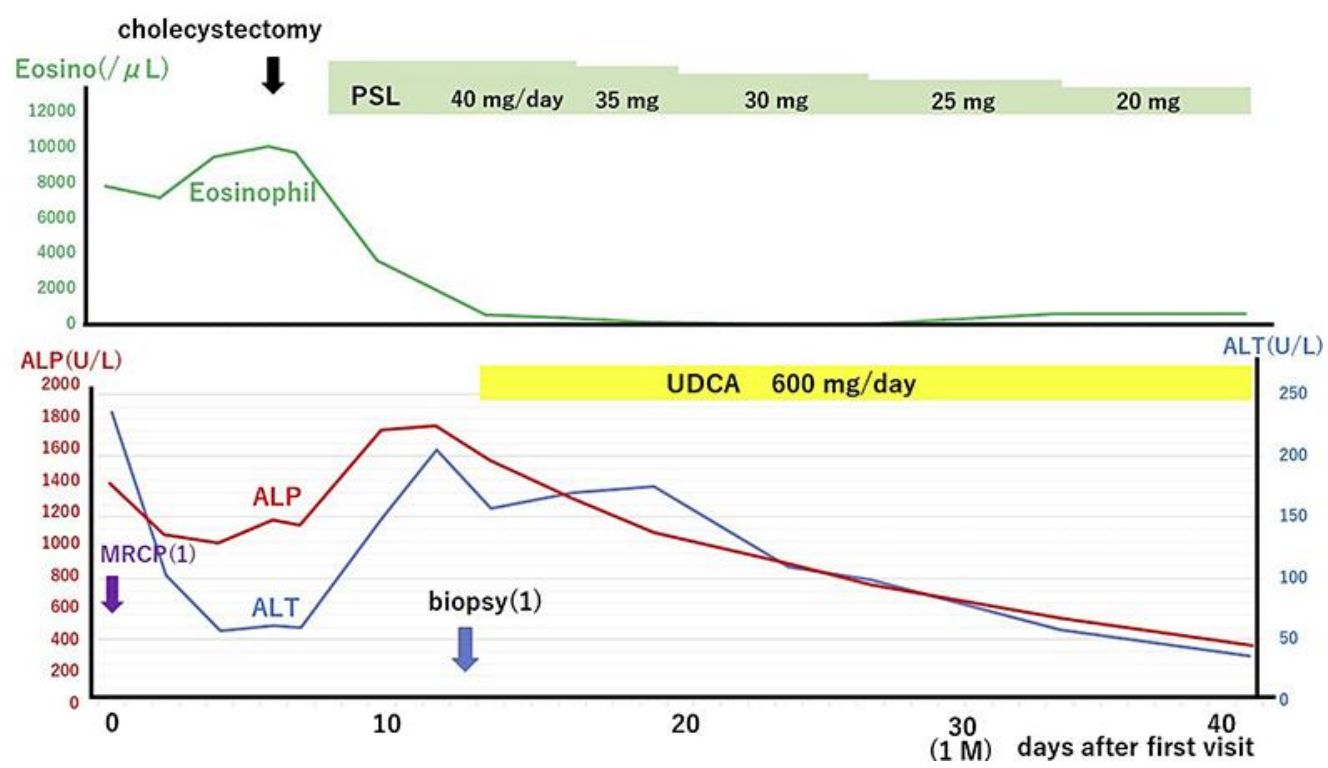

Fig. 3. Clinical course from the first visit until 40 days after the first visit. PSL, prednisolone; UDCA, ursodeoxycholic acid; Eosino, eosinophils; ALP, alkaline phosphatase; ALT, alanine aminotransferase; MRCP, magnetic resonance cholangiopancreatography.

\section{Karger'}




\section{Case Reports in Gastroenterology}
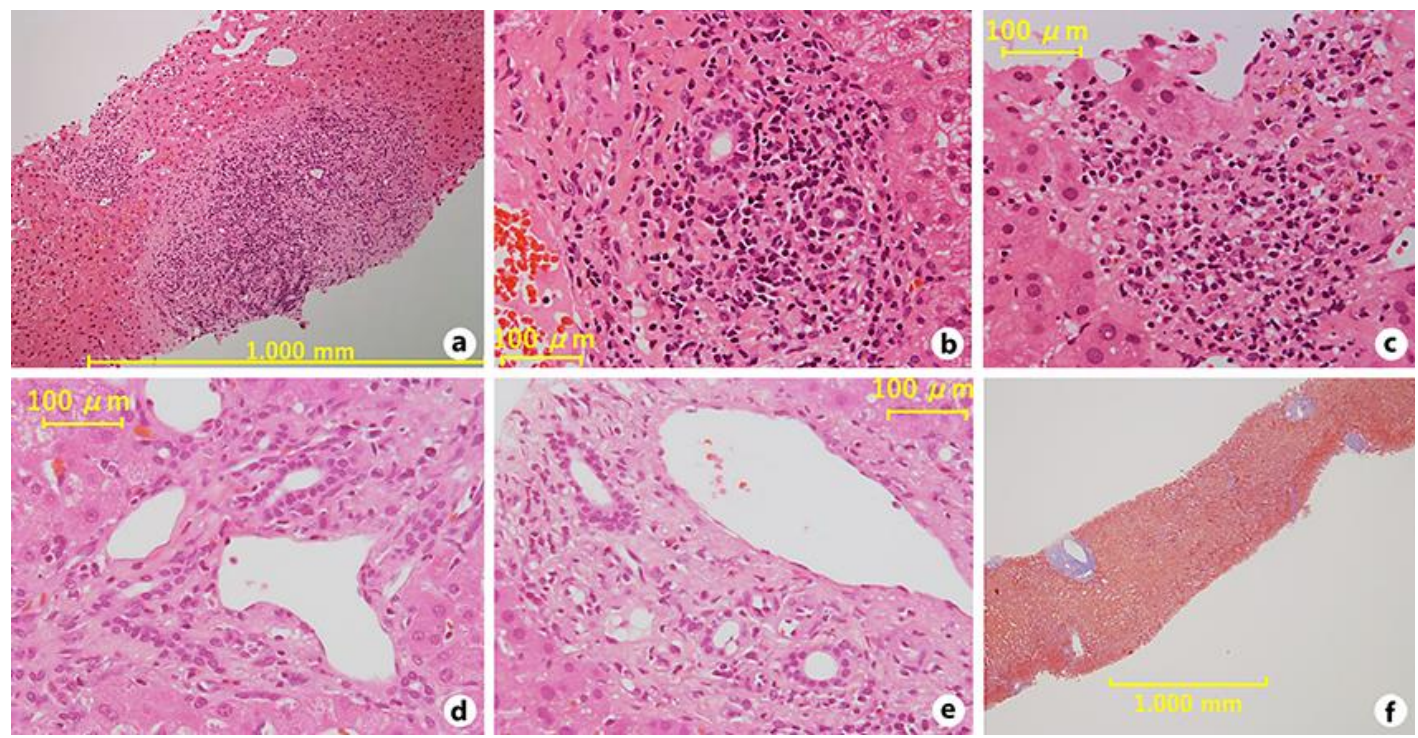

Fig. 4. a-c The histological findings of the first needle biopsy of the liver conducted 13 days after the first visit (HE staining). a Portal areas were moderately widened with moderate to severe infiltration with inflammatory cells. There was mild to moderate fibrosis at the portal areas. $\mathbf{b}$ Infiltrating eosinophils were replaced by plasma cells and lymphocytes, resulting in the histological image mimicking autoimmune hepatitis. c In the liver parenchyma, spotty necrosis and focal necrosis with lymphocyte and plasma cell infiltration were observed. There were no signs of portal phlebitis. d, e The histological findings of the second needle liver biopsy 3 months after the first visit (HE staining). Mild lobular and interface hepatitis with a small number of infiltrating eosinophils and plasma cells. $\mathbf{f}$ Mild fibrosis. 


\section{Case Reports in Gastroenterology}

Case Rep Gastroenterol 2021;15:232-243

DOI: $10.1159 / 000512420$

(c) 2021 The Author(s). Published by S. Karger AG, Basel www.karger.com/crg

Shimomura et al.: Eosinophilic Cholangitis with Poor Prognosis after Corticosteroid- and Ursodeoxycholic Acid-Related Remission of Peripheral and Peribiliary Eosinophilia

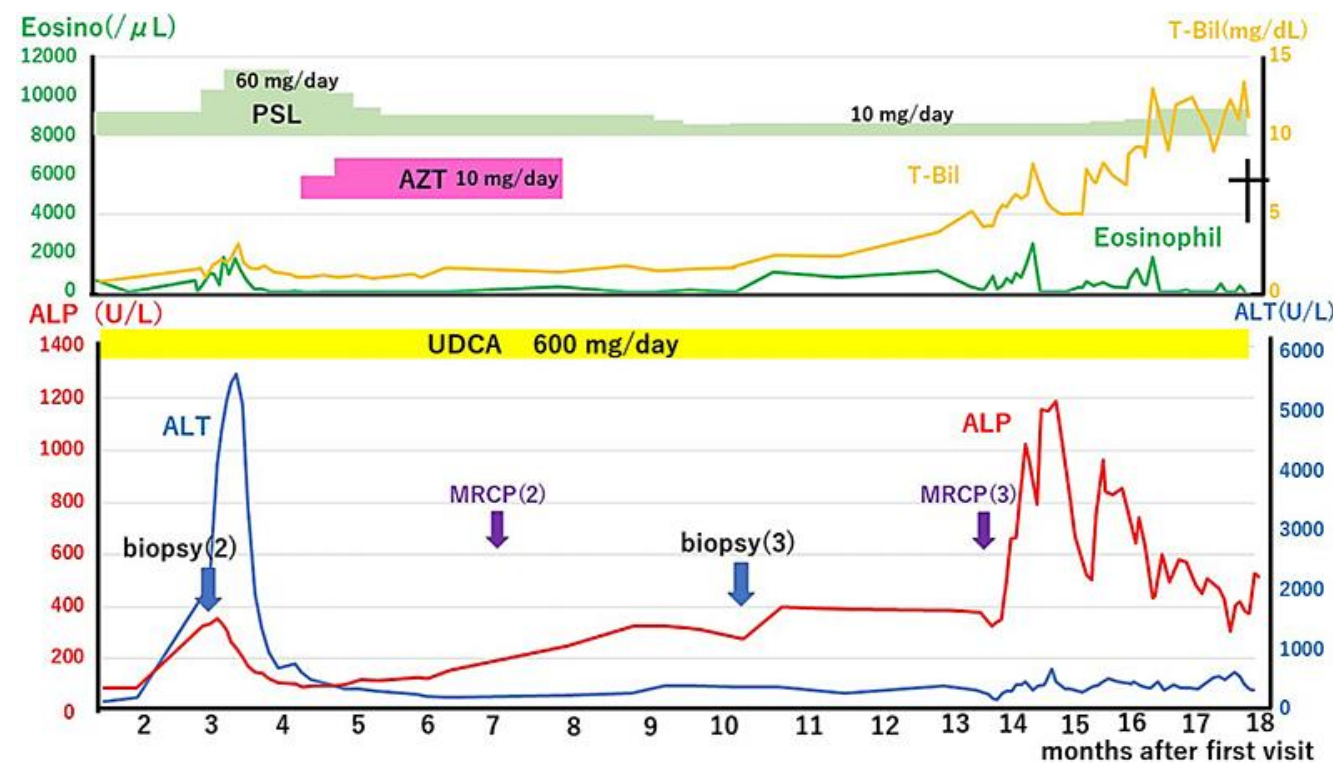

Fig. 5. Clinical course from 2 months after the first visit until death. PSL, prednisolone; UDCA, ursodeoxycholic acid; Eosino, eosinophils; ALP, alkaline phosphatase; ALT, alanine aminotransferase; MRCP, magnetic resonance cholangiopancreatography.
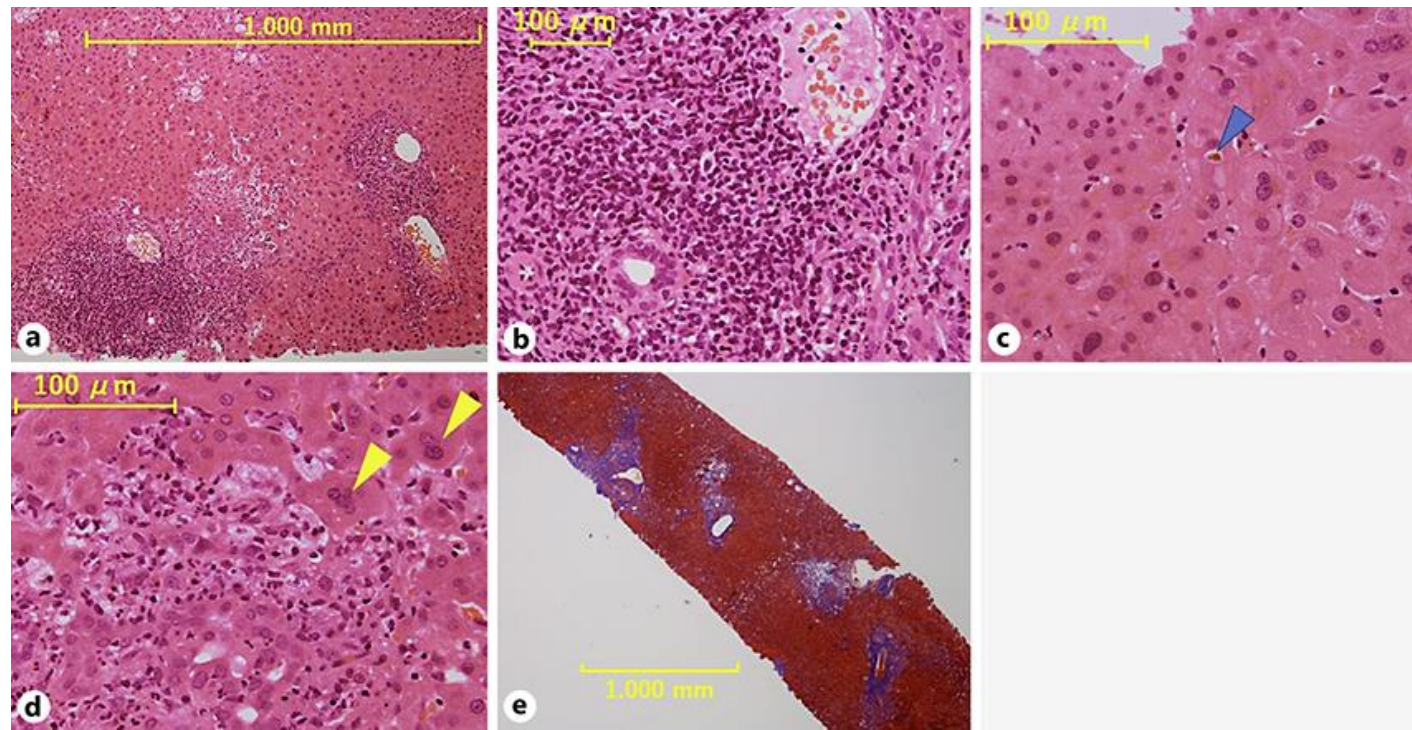

Fig. 6. The histology of the third needle biopsy of the liver 10 months after the first visit. a-d HE staining; e Masson's trichrome staining. There was interface hepatitis with massive infiltration with lymphocytes (a) that occasionally formed lymph follicles (b). Eosinophilic infiltration was scarce. Besides, there were signs of bile stasis, such as intracytoplasmic bile pigment, bile plug in the bile canaliculi (c, blue arrowhead), and feathery degeneration of hepatocytes (d). $\mathbf{d}$ Some hepatocytes presented the morphology of multinucleated giant cells (yellow arrowheads). e Portal fibrosis showed slight trend to extension toward the adjacent portal areas.

\section{Karger'}




\section{Case Reports in Gastroenterology}

\begin{tabular}{l|l}
\hline Case Rep Gastroenterol 2021;15:232-243 \\
\hline DOI: 10.1159/000512420 & $\begin{array}{l}\text { @ 2021 The Author(s). Published by S. Karger AG, Basel } \\
\text { www.karger.com/crg }\end{array}$ \\
\hline
\end{tabular}

Shimomura et al.: Eosinophilic Cholangitis with Poor Prognosis after Corticosteroid- and Ursodeoxycholic Acid-Related Remission of Peripheral and Peribiliary Eosinophilia
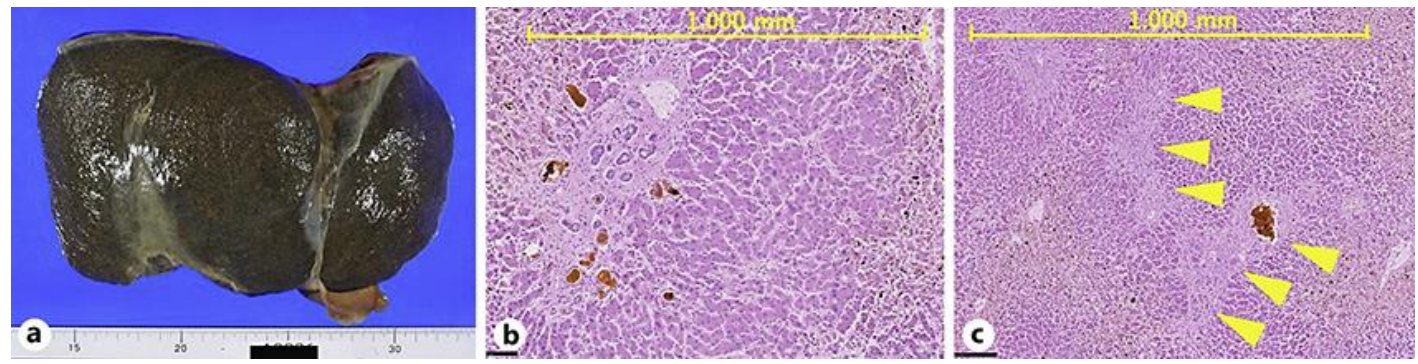

Fig. 7. Autopsy findings of the liver. a Macroscopically, the dark green liver which weighed $723 \mathrm{~g}$ showed slightly micronodular appearance. b, c Microscopically, obstruction and destruction of the interlobular biliary ducts resulted in bile stasis and periductular fibrosis, which extended to the adjacent portal areas and formed bridging fibrosis (yellow arrowheads). 